\title{
Transformaciones del mundo globalizado y derecho de propiedad durante la vigencia del Código Civil peruano: veinte años de saqueo imperialista y el potencial de resistencia de los juristas*
}

Ugo Mattei $^{* *}$

1. En tiempos recientes, se ha puesto de moda entre los juristas la celebración de los cumpleaños de los códigos civiles. El Código de Napoleón, el más antiguo y prestigioso de todos, padre de los códigos peruanos precedentes — de 1852 y 1936 - , ha tenido fiestas, por sus doscientos años, en Francia, Bélgica, Italia, Estados Unidos, Escocia, solo por mencionar aquellas a las que he sido invitado. Los sesenta años del Código Civil italiano de 1942, que muchos consideran el modelo del «dueño del santo» que saludamos hoy (afortunadamente, no tenemos problemas sobre el género, masculino, que le corresponde a los códigos civiles, como sí los hay para establecer el género que debe reconocerse a la expresión «common law») también ha tenido sus celebraciones en Turín, Roma y otras ciudades.

Este magnífico congreso que nos reúne en la Universidad Católica del Perú, por cuya organización debemos estar agradecidos al decano Armando Zolezzi Möller, así como a los profesores Gastón Fernández Cruz y Leysser L. León, obedece a las mismas razones: el Código Civil peruano entró en vigor, en efecto, el 14 de noviembre de $1984 .{ }^{1}$ Para mí, es un honor estar

El presente trabajo, originalmente titulado "Global Transformations and Property Law in the Lifespan of the Peruvian Civil Code: Twenty Years of Imperialist Plunder and the Resisting Potential of Legal Scholarship», corresponde a la ponencia elaborada por el autor para el congreso "El Código civil del 1984: veinte años de vigencia. Pasado y futuro», organizado por Pontificia Universidad Católica del Perú, en Lima, del 8 al 12 noviembre del 2004.

Traducción de Leysser L. León. Profesor de Derecho Civil de la Pontificia Universidad Católica del Perú. Diplomado en Lengua y Cultura Italianas por la Università per Stranieri di Perugia (Italia).

** Profesor "Alfred and Hanna» de Derecho Internacional y Comparado en la Universidad de Hastings, California. Profesor ordinario de Derecho Civil en la Universidad de Turín.

1 El Código Civil peruano de 1984 entró en vigor el 14 de noviembre de 1984 y está estructurado como sigue: 
presente y poder participar de las celebraciones hoy, dos días antes de la fecha central, a través de esta ponencia, con la que aspiro a tributar un sencillo y simbólico homenaje. Puesto que el código es, para la tradición del derecho civil, la más significativa expresión de la cultura jurídica de un país, y dado que la preparación de este específico código concentró el trabajo de juristas peruanos por más tiempo que los años que está cumpliendo (recuérdese que la Comisión Encargada del Estudio y Revisión y del Código Civil de 1936 fue instituida mediante decreto supremo 95, del 1 de marzo de 1965), ${ }^{2}$ mi homenaje de hoy quiere incidir en el espíritu de respeto por el pasado y expresar mis esperanzas sinceras en el futuro de la ciencia jurídica peruana y, más en general, latinoamericana.

Mi propósito es contribuir a este Congreso planteando el tema de la codificación del derecho de propiedad desde una perspectiva global, teniendo en debida cuenta el espíritu, la economía, el contexto y la ideología de una rama del derecho - la propiedad, justamente- que, más que ninguna otra, constituye la base institucional del capitalismo de mercado.

Mi tesis es que los códigos civiles cuentan más por su simbolismo que por su texto, solo que en Perú, y en muchos otros países, el formalismo y el apego a los textos de las culturas jurídicas importadas de Europa, así como el desarrollo de ideologías impuestas por el dominio tecnocrático estadounidense,

Título Preliminar (relativo a la publicación, efectos y aplicación de las leyes en general) (artículos I-IX).

Libro I. Personas (arts. 1-139).

Libro II. Negocios jurídicos (arts. 140-232).

Libro III. Derecho de familia (arts. 233-659).

Libro IV. Derecho de sucesiones (arts. 660-880).

Libro v. Derechos reales (arts. 881-1131).

Libro VI. Derecho de obligaciones (arts. 1132-1350).

Libro VII. Fuentes de las obligaciones (arts. 1351-1988).

Libro VIII. Prescripción y caducidad (arts. 1989-2007).

Libro IX. Registros públicos (arts. 2008-2045).

Libro X. Derecho internacional privado (arts. 2046-2111).

Título final (disposiciones relativas al período de transición) (arts. 2111-2122).

2 Como culminación de un proceso que padeció interrupciones, la Comisión, creada en 1965, entregó un Anteproyecto de Código Civil, al que iban a incorporarse diversos cambios en el período sucesivo (dicho Anteproyecto se publicó en la Revista peruana de derecho internacional, vol. 77, diciembre de 1980). Una Comisión Revisora fue creada mediante ley 23403, del 27 de mayo de 1982, con el fin de someter a examen el Anteproyecto. Dicha Comisión fue presidida por Felipe Osterling Parodi y estuvo conformada por tres senadores y tres diputados, en representación de sus respectivas Cámaras, así como por tres abogados designados por el Ministerio de Justicia. Según el artículo 2 de la ley 23576, el Proyecto aprobado por la Comisión Revisora abrogó el Código Civil peruano de 1936, así como las normativas precedentes. Finalmente, el nuevo Código Civil entró en vigor mediante el decreto legislativo 295, del 24 de julio de 1984, firmado por el presidente Fernando Belaúnde Terry. De todo ello se informaba en la nota "Peru: Private International Law in New Civil Code of 1984». En I. L. M., vol. 24, 1985, p. 997. 
han conspirado para traicionar los contenidos sociales, los preceptos y los símbolos de la más reciente generación de códigos. Así las cosas, códigos civiles como el peruano, o el brasileño, que es aún más reciente, corren el riesgo de ser intrepretados como depositarios de reglas que protegen el statu quo y no como como documentos progresistas, insipirados en la búsqueda de la justicia social. En América Latina, como en otras partes del mundo, las instituciones jurídicas importadas desde el centro del capitalismo han legitimizado y encubierto, entonces, un proceso de dominación económica y política, un proceso al que la cultura jurídica civilista tradicional, en primer término, y la predominante retórica estadounidense del rule of law, ${ }^{N T}$ después, han dotado de un grado de legitimidad intelectual. Atendiendo a las transformaciones económicas de la globalización, intentaré demostrar que los verdaderos problemas «a saber: la distribución de los recursos, la desigualdad social y la segregación étnica- en el Perú y en América latina, que son cruciales en lo tocante al derecho de propiedad, no han sido aún tratados ni sometidos a discusión por los juristas, prisioneros del mito de la neutralidad política del derecho civil privado y a la postre cautivos de la ideología tecnocrática del análisis iuseconómico del desarrollo, de inspiración estadounidense. ${ }^{3}$

En la parte conclusiva de mi ponencia, explicaré por qué las instituciones jurídicas producidas en el indicado centro del capitalismo son una mercadería que es peligrosa importar hacia las zonas periféricas. Dichas instituciones perpetúan un patrón de dominación y explotación que debería ser rechazado. En la evaluación de los últimos veinte años del desarrollo que ha tenido el derecho, en el marco del Código Civil de 1984, la cultura jurídica peruana no debería olvidar que el desafío para América Latina es conseguir elaborar una organización institucional propia, a fin de emanciparse de la dominación neocolonialista.

2. En los últimos días de 1977, una de las multitudes más grandes que se hayan congregado en las calles de Lima acompañaba, camino al cementerio, el féretro de Juan Velasco Alvarado. Su gobierno fue el último que prestó atención, desde un principio, al proceso de reforma económica y social, en interés de las masas de desposeídos. Las reformas de Velasco incidieron,

NT Aunque hay quien propone traducir esta expresión inglesa como "estado de derecho»e, incluso, como «imperio del derecho», prefiero mantener la expresión «rule of law» en inglés, de uso generalizado entre los juristas e imprescindible cuando el discurso asocia la figura, críticamente, con la política de un país preciso. Como se sabe, "Estado de derecho» proviene, en cambio, del alemán "Rechtsstaat».

Véase COOTER, R., E. BuSCAGLIA y W. RATLIFF (eds.). The Law and EConomics of Development. Greenwich (Conn.), 1997. 
cómo no, en el derecho de propiedad con el afán de romper la apremiante dialéctica entre «latifundio» y «minifundio», que, por quinientos años, había constituido la estructura institucional fundamental de la explotada economía de América Latina. El general Velasco, nacido en la pobreza, en una pequeña y remota ciudad del norte del Perú, entendió que, en el derecho de propiedad, el servir al interés de los desposeídos hace que también el interés general del país resulte beneficiado. Luego del golpe de 1968, el Gobierno militar, en lo que ha sido definido como «la más profunda y rica decisión de cambio» en el Perú, "puso en marcha una genuina reforma agraria, y abrió las puertas para la recuperación de los recursos naturales usurpados por el capital extranjero». ${ }^{4}$ No mucho tiempo después de la muerte de Velasco, la revolución también feneció, con su proceso creativo estrangulado por préstamos, chantajes y a causa de la debilidad de un proyecto paternalista, carente de una base popular organizada. Desde la óptica del impacto social, las leyes de reforma no fueron más efectivas que las muchas prescripciones contenidas en la recopilación de las Leyes de Indias, en el siglo XVII, en las que se establecían iguales derechos para los indígenas y españoles en lo tocante a la explotación de minas, así como la prohibición de infringir los derechos de los indios. Aun con aquellas prescripciones en vigor, las minas de Cerro Rico, en Potosí, fueron el escenario de la esclavitud de los indígenas por trescientos años, cual si se tratara de un monstruo infernal, que consumió a ocho millones de ellos, mientras se aprovisionaba de recursos económicos al Imperio británico, con una secuela de destrucción para América Latina.

Pocos años antes de que Velasco empezara a prestar atención al tema de la distribución de la propiedad, otro héroe popular, Salvador Allende, emprendía un esfuerzo similar en el vecino país de Chile. Pero su generosa disposición para hacer reformas, que desarrolló el socialismo con una innovadora visión del rule of law, pereció junto con él y los miles de «desaparecidos» del régimen brutal de Pinochet, auspiciado por Estados Unidos. Cuando yo visité el Banco Mundial, en 1998, el caso de Chile fue presentado, descaradamente, como una historia exitosa. Hoy en día, aquellas mismas fuerzas dominantes estadounidenses se sirven del rule of law como el aparato ideológico más poderoso del gobierno globalizado y como una forma de encubrir las prácticas letales que vienen operando en Medio Oriente. ${ }^{5}$ Iniciativas para la reforma social, similares a las del general Velasco y culminadas, invariablemente, de manera trágica, fueron emprendidas du-

Véase Galeano, E. Open Veins of Latin America. Ed. revisada. Nueva York, 2000, p. 269.

5 La crítica y el cotejo de las prácticas neoliberales de dominación actuales con las de la colonización es desarrollada en la obra, próxima a publicarse, de MATTEI, Ugo y Laura NADER. Plunder. Imperial Uses of Rule of Law. 
rante la época de la Guerra Fría en otros países que han preservado la «opción» capitalista en América Latina, como Guatemala, Bolivia, Uruguay, Brasil y Argentina. La "doctrina Monroe», expuesta, en 1898, para legitimar los derechos de sucesión imperial de Estados Unidos, ha sido impiadosa para con tales iniciativas de reforma social, pues su interés siempre ha sido preservar en un mínimo nivel el costo de la mano de obra laboral utilizada en la extracción en serie de recursos, así como el costo de una intensiva explotación agroindustrial. Como bien sabemos, conforme a una teoría económica básica, una alta tasa de desempleo, una pobreza extendida y una estructura del derecho de propiedad que impida la subsistencia y desarrollo en el entorno rural conforman la fuerza más poderosa para mantener bajo el precio de la mano de obra laboral, ya industrial, ya rural.

Al comienzo del decenio 1980-1990, la última guerra imperialista británica en América Latina, en las islas Malvinas, simbolizó, en el más alto nivel internacional, el nacimiento del orden mundial neoliberal actualmente en vigor, de preeminencia angloestadounidense. Este neoliberalismo, que desmantela la protección social para favorecer la industria militar y las políticas de represión, fue inaugurado por la revolución de Reagan y Thatcher, como un esfuerzo para poner término a la guerra fría. La retórica triunfante de la victoria en la guerra fría iba a "constitucionalizar» el neoliberalismo y a permitir a sus doctrinas simplistas la conquista del bando de la oposición: la llamada «tercera vía», simbolizada por el dúo conformado por Clinton y Blair. En la actualidad, el neoliberalismo es interpretado como "sin guantes» ${ }^{\text {NT1 }}$ por las doctrinas neoconservadoras de Bush, que dominan todas las ramas de aquel sistema de «ajustes y balances» de la harto celebrada democracia estadounidense. En el plano internacional, la política neoliberal, que porta su nítida teoría del derecho de propiedad, basado en la eficiencia, es interpretada por la Organización Mundial del Comercio (OMC), el Fondo Monetario Internacional (FMI), por el Banco Mundial y sus oficinas regionales (el Banco Interamericano de Desarrollo) en los mismos términos que imperan entre los Gobiernos que integran el club G7-G8.

3. Hace doscientos años, Napoleón codificó las ideas sobre la propiedad que podían servir mejor a las necesidades económicas de la naciente burguesía comercial europea. Dichas ideas, cuyas raíces se encuentran en el derecho natural, fueron las mismas de la doctrina usada por Cortés y Pizarro para justificar la muerte y el saqueo en América Latina como una adquisición

NT1 La expresión "capitalism with the gloves off» se ha vuelto común para identificar una sociedad con poca seguridad, debido tanto a un mínimo desarrollo del estado de bienestar cuanto a un incipiente mercado del trabajo. Ya se traduce al castellano como "capitalismo sin guantes». 
«originaria» de tierras que eran consideradas «de nadie», sin propietarios, y en el nombre de un soberano cristianamente instituido. El Perú importó la estructura fundamental del Código napoleónico en 1852 y luego en 1936, pero ello no tuvo ningún impacto en una economía gobernada y dominada, en los hechos, por el capitalismo británico, antes y después de la proclamación de la Independencia, por San Martín. El derecho privado bien puede vivir, hoy como ayer, sin ninguna estructura de poder, tal cual lo demuestran innumerables estudios de especialistas. Sin importar la forma jurídica adoptada por el derecho privado en el Perú, los derechos de propiedad siempre han estado gobernados por la estructura del endeudamiento internacional, ya que los españoles asesinaban y saqueaban en América Latina para pagar sus deudas con banqueros británicos. Uniformándose a un destacable patrón de continuidad, la burguesía local poscolonial, incapaz de crear un mercado local debido a la trágica distinción entre latifundio y minifundio, persistió en las actividades de extracción, del guano a la madera y a los minerales, que se vendieron a precios ínfimos, las más de las veces al crédito, a los ingleses, nada más que para solventar un consumismo de lujo y los hábitos producidos por sus gustos afrancesados. En la moda, así como en el derecho, la forma es francesa, el sustrato económico es inglés y las víctimas son las masas.

En la historia del comercio internacional peruano, los italianos tuvieron un papel bastante marginal. Los banqueros de Génova invirtieron su dinero en las primeras expediciones españolas y participaron, al lado de sus homólogos ingleses y suizos, de la creación de una economía más globalizada, mas no de la construcción de una estructura política para el colonialismo temprano. El mármol de Carrara fue una de las extravagancias a la moda en las casas coloniales más ricas y, a inicios del siglo pasado, un buen número de italianos desposeídos emprendieron el camino hacia América Latina, principalmente a Argentina y Brasil. Quizás podríamos incluir, entre las exportaciones italianas, al Código Civil de 1942, lo cual podría darnos una explicación de la presencia de tantos académicos italianos en este Congreso, ${ }^{6}$ solo que Italia es vista, por lo general, como un «entorno de recepción» ${ }^{7}$

El Código Civil italiano de 1942 influyó de manera significativa en la codificación peruana de 1984. Véase MuRILlO, María Luisa. "The Evolution of Codification in the Civil Law Legal Systems: Towards Decodification and Recodification». Journal of Transnational Law \& Policy, vol 11, 2001, pp. 163 y 176 (quien cita el trabajo de DíEZ-PICAZO Y PONCE DE LEÓN, Luis. "Codificacion, Descodificacion y Recodificacion». Anuario de derecho civil, abril-junio, 1992, pp. 473-484). Más recientemente, resulta enriquecedora la consulta del excelente libro de LEÓN, Leysser L. El sentido de la codificación civil. Estudios sobre la circulación de los modelos jurídicos y su influencia en el Código Civil peruano. Lima, 2004.

Véase LÓPEZ MeDINA, Diego. Teoria impura del derecho. Bogotá, 2004. 
de otros derechos, de modo que apreciarla, ahora, como una cultura jurídica de exportación es una nueva experiencia para mí.

La codificación civil italiana de 1942 produjo una interesante síntesis entre la teoría económica y política del corporativistmo fascista, que negaba el conflicto de clases, y el academicismo liberal tradicional, que cambiaba las nociones de las funciones sociales de los derechos que amenazaban el apreciado statu quo. En Italia, el debate sobre la inspiración política del Código Civil ha sido bastante intenso, incluso en tiempos recientes; ${ }^{8}$ para mis propósitos, sin embargo, hay dos puntos que resultan de interés. En primer lugar, el Código Civil italiano debe ser leído en conexión con la Constitución republicana de 1948, que ha inyectado en su interpretación una dosis de pensamiento socialista, debido al importante papel desempeñado en la Asamblea Constituyente por el líder comunista Togliatti y por el líder socialcatólico Dossetti. Desde esta óptica, el Código Civil italiano debe apreciarse como un destacado ejemplo de legislación socialmente responsable, aunque traicionado, de forma sistemática, por las tendencias globalistas y neoliberales posteriores al decenio 1980-1990. La cultura jurídica italiana, para decirlo claramente, no ha sido capaz de desenvolver ningún papel efectivo de contraste o de oposición a tales tendencias, que han incluido reformas inspiradas en las doctrinas del FMI en temas como la propiedad intelectual, vivienda, trabajo, la corporate governance y el patrimonio cultural. En segundo lugar el libro que el Código dedica a la propiedad ha sido una ocasión perdida, incapaz de reflejar la real novedad de la unificación del derecho civil y el derecho comercial. En consecuencia, la ruptura que dicho Código representa respecto del modelo napoleónico, plasmada en normas como las concernientes a las inmisiones y a la aemulatio, no ha sido profunda, por lo cual el derecho de propiedad italiano se encuentra ubicado, actualmente, fuera del Código Civil. ${ }^{9}$

La recepción en el Perú de una pieza de legislación socialmente responsable en tiempos de neoliberalismo (1984) puede tener, entonces, solo dos significados: que la cultura jurídica peruana ha deseado oponer resistencia a dicha tendencia (solo que, en tal hipótesis, los italianos no seríamos, ciertamente, un buen modelo por seguir) o bien que, como yo estoy tentado a creer, el Código Civil no cuenta mucho en el panorama de las fuentes del derecho, por lo menos en lo tocante al derecho de propiedad. Con todo, el símbolo para un papel socialmente responsable del derecho se encuentra en

Cfr. FERRI, G. B. Filippo Vassalli o il diritto civile come opera d'arte. Padua, 2002.

Véase Gambaro, A. La proprietà, en Trattato di diritto civile e commerciale diretto da Antonio Cicu e Francesco Messineo, continuato da Luigi Mengoni. Milán, 1998. Véase también MATTEI, U. «Il diritto di proprietà». En Trattato di diritto civile diretto da Rodolfo Sacco. Turín: UTET, 2001. 
el lugar que le corresponde. Toca a los peruanos obrar para expandirlo o rechazarlo.

Permítanme añadir que el Perú representa un entorno de pluralismo jurídico. ${ }^{10}$ Desde la perspectiva del derecho comparado, la cultura jurídica de América Latina está lejos de ser unitaria, tanto de un Estado a otro, como herencia de la partición colonial cuanto en el marco del Estado moderno. Esta «división en módulos» tradicional es particularmente clara si se tiene en cuenta que la mayor parte del derecho constitucional contemporáneo está ampliamente influenciada por el derecho estadounidense, mientras que el derecho privado se mantiene enraizado en la tradición romanista. ${ }^{11}$ Sin embargo, las influencias del common law en el derecho privado no han sido escasas y es fácil percibirlas «en relación con la adopción del express trust por algunos países centroamericanos y sudamericanos». ${ }^{12}$

El derecho privado latinoamericano deriva, en gran medida, del derecho español y portugués. Los conquistadores, durante su implacable explotación de los nuevos territorios, transfirieron también sus instituciones y tradición jurídica al «nuevo mundo», porque la modernización del derecho constituía un componente ideológico importante del proyecto colonial. La colonización europea, empero, no desplazó por completo la tradición jurídica de la población nativa (aztecas, mayas, incas, etc.). ${ }^{13}$

Incluso en la actualidad, aquellas tradiciones consuetudinarias mantienen cierta importancia, particularmente en Perú, entre la gente de ascendencia incaica y, más en general, en el sector marginal de la población. En consecuencia, en los pequeños centros urbanos de lo más íntimo del continente y en los pueblos jóvenes de Lima y de otras grandes urbes latinoamericanas, la vida en sociedad es organizada por una mayoría de la población de acuerdo con la costumbre jurídica, que nada tiene que ver con aquel derecho formal, autoritativo y docto del Estado, que se enseña en las universidades según la antigua tradición del civil law. Como alguien ha escrito, una gran mayoría de la población latinoamericana vive con arreglo a un «derecho informal que no necesita abogados ni jueces». ${ }^{14}$

10 Véase Guadagni, M. "Legal pluralism». En P. Newman (ed.). The New Palgrave. A Dictionary of Economics and the Law. Londres, 1998.

11 Véase SCHLESINGER, R., BAADE et. al. Comparative Law. 5. ${ }^{a}$ ed. Mineola (Nueva York), 1988 , p. 500 y nota 7.

12 Ib., p. 315 y ss.

13 Véase Merryman, J. H. The Civil Law Tradition. 2. ${ }^{a}$ ed. Stanford, 1985. Véase también, para una discusión sobre las tempranas falencias en la consideración de las especificidades del derecho latinoamericano, GARDNER, J. Legal Imperialism. Madison, 1980.

14 PÉREZ PERDOMO, R. "Imperativos y alternativas de la reforma de la educación jurídica en América Latina». En A. Giuliani y N. Picardi. L'educazione giuridica. 2. Milán, 1979, p. 287. 
Sobre los cimientos del derecho consuetudinario, los españoles, portugueses y otros europeos establecieron su derecho e instituciones jurídicas, en ambos casos, por soberanía directa, o bien por dominación indirecta, basada en el crédito y orientada al desarrollo de un sistema estable de extracción para fines de exportación de materias primas a ser consumidas en Occidente. No solamente los latifundios, sino también la verdadera idea del Estado colonial centralizado, dominado por puertos comunicados únicamente con la metrópolis colonial, obedecían a esta lógica. En América Latina, encontramos, entonces, un fenómeno de estratificación jurídica cuyo segundo estrato estaba representado por el derecho civil (español y portugués), tal cual era aplicado durante la experiencia colonial. El tercer estrato fue generado durante el siglo XIX cuando - una vez derrotado la dominación colonial- los países de América Latina comenzaron a codificar. En dicho marco, la codificación no significó rupturas sustanciales con el pasado. En el moderno Estado latinoamericano se promulgó, a partir de entonces, una importante cantidad de "derecho político» (leyes especiales) al compás — de acuerdo con la historia local— de las revoluciones sociales, reformas e involuciones autoritarias, cuya constante ha sido la preservación de un débil papel de la jurisprudencia en la conformación del derecho, especialmente en aquellos países donde existen disposiciones expresas que prohíben el case law. Atendiendo al débil estatus de la jurisprudencia, el papel de controlar el derecho político, así como toda la creación de un marco jurídico ordenado, es asumido, en América Latina, por los juristas, por los estudiosos del derecho.

Entre las fuentes del derecho local no promulgado, son los juristas, en efecto, los que ejercen la mayor influencia. En nuestros días, con la desaparición del Estado periférico, como efecto del neoliberalismo, el Banco Mundial, el FMI, la OMC imponen su visión de los property rights (la concentración de la propiedad intelectual representa el nuevo latifundio) y hacen que para muchos resulte imposible toda iniciativa de reforma de la propiedad o de redistribución social de la riqueza. Así se produce un nuevo estrato del derecho, de cuño estadounidense las más de las veces, que rige el sector formal de la economía, que toma su prestigio de las facultades de Derecho de Estados Unidos y que sirve, como siempre, a los intereses del capitalismo extranjero y a los de sus camaradas locales. ${ }^{15}$

El derecho de propiedad contenido en el Código Civil peruano de 1984 ha sido derrotado, entonces, y ha quedado al margen por dos fenómenos opuestos que, por paradójico que resulte, son complementarios. En el nivel

15 Véase Dezalay, I. y B. G. GaRth. The Internalization of Palace Wars. Chicago: University of Chicago Press, 2002. 
inferior, muchas personas no han sido afectadas por la forma, inspiración y sustancia de aquel derecho, porque ellas se rigen por una forma alternativa de legalidad, originada por la desesperación, menesterosa de solidaridad, e impuesta por la dificultad de subsistir con menos de dos dólares al día. En el nivel superior, el derecho de propiedad codificado y su inspiración "social» han sido derrotados por el poderoso estrato del derecho imperialista, que gobierna con la implacable lógica del imperialismo de mercado.

4. He presentado al general Juan Velasco Alvarado como el símbolo de una reforma social (no necesariamente progresista, sino muchas veces paternalista o populista), inspirada en el interés de la población local y no en los intereses del capital extranjero. Dicha iniciativa, que fue compartida por otros países de América Latina, tuvo lugar en un momento histórico en el cual, debido al equilibrio de la guerra fría, las élites dirigentes estaban en verdad temerosas de la revolución socialista, y ello no era de extrañar, dado el ejemplo de Cuba. ${ }^{16}$ Sin embargo, para la pacificación de las masas latinoamericanas, los extranjeros que daban las reglas prefirieron el castigo del terror a los incentivos del bienestar, de modo que aquellos programas de reforma social nunca tuvieron eficacia real.

Nociones como la "función social del derecho de propiedad», incorporada en la filosofía del Código Civil peruano de 1984 y, más recientemente, en el nuevo Código Civil brasileño, a pesar de su ambigüedad política, fueron desarrolladas en Europa, justamente, como un aliciente para responder a los miedos que despertaba la revolución socialista a inicios del siglo XX. Dada su naturaleza, dichas nociones fueron tremendamente existosas y se globalizaron en una amplia variedad de escenarios geográficos hacia el decenio 1970-1980 del siglo pasado. ${ }^{17}$ Pero, en los primeros años del decenio 1980-1990, incluso estas tendencias moderadas hacia la distribución de los recursos, que buscaban posibilitar el desarrollo de un mercado local y, con ello, el rompimiento de las cadenas de la dominiación imperialista, fueron abandonadas. La ola triunfal de un camino económico neoliberal, que forzaba a los productores locales a competir con productos extranjeros altamente subsidiados, bajo la sombra de la OMC y de los llamados «Programas de Ajuste Estructural» (Structural Adjustment Programs), estuvo acompañada del castigo de una violenta represión de los opositores, en lugar de que se dieran incentivos para la redistribución. La pobreza ex-

16 Véase el excelente trabajo de CASTAÑEDA, J. G. Utopia Unarmed. The Latin American Left after the Cold War. Nueva York, 2004.

17 Véase KENNEDY, Duncan. "Two Globalizations of Law and Legal Thought: 1850-1968». Suffolk University Law Review, 2003, p. 631 y ss. 
trema resulta funcional, cómo no, para los programas «maquilladores», para las zonas de tratamiento económico especial y para las monoculturas. A su vez, el control violento de la oposición es funcional para las necesidades de empresas que tienen intereses en la privatización de las cárceles y en contar con vigilantes privados en un vecindario que es rico, pero que también está circundado por la miseria.

Otro peruano de renombre internacional, Hernando De Soto, puede ser visto como el símbolo de la arrogancia descarada con la cual, debido a su victoria en la guerra fría, el imperialismo capitalista de Occidente impone sus valores e intereses en escenarios débiles. El derecho de propiedad vuelve a estar involucrado en esta historia. Atendiendo a aquel tipo de teorías, el camino occidental del desarrollo económico tiene éxito cuando se presenta a sí mismo como una historia de éxito. Al mismo tiempo, se borra el hecho de que el saqueo imperialista juega un papel mucho más importante que el derecho de propiedad doméstico en el desarrollo capitalista occidental. Este desarrollo capitalista occidental tiene lugar por causa de la explotación colonial, esto es, por un sistema de prolongada ilegalidad global que (paradójicamente) ha utilizado el derecho (y lo sigue haciendo) como uno de sus más poderosos aparatos ideológicos. Sin embargo, De Soto, en esos dos best sellers, mundialmente aclamados, que son El Otro Sendero y The Mystery of Capital, acredita el desarrollo occidental como si fuera la mejor estructura doméstica de los property rights y reprocha a los países pobres la carencia de una estructura semejante. Con ello, ciñéndose a la tradición ideológica más común del Banco Mundial, se descargan las culpas del subdesarrollo en las víctimas y no en el opresor.

El énfasis de De Soto y de muchos de sus admiradores, entre los que se cuentan economistas, abogados y policy makers, se ha centrado en la habilidad de un sistema occidentalizado y desarrollado de propiedad para usar los activos físicos como un instrumento para producir capital. El sistema de propiedad occidentalizado permitiría a aquellos activos conseguir una «vida invisible y paralela, más allá de su existencia material», ${ }^{18}$ solo que, contrariamente, los sistemas de propiedad en países como Perú o Brasil, a despecho de la modernidad de sus códigos civiles, carecen de medios comparativos de documentación y formalización que permitan integrar la propiedad en un amplio esquema de inversión. El capital muerto que de ello resulta disuade a muchos propietarios, sistemáticamente, de constituir hipotecas con fines de inversión en sus negocios. Adicionalmente, la documentación sobre la titularidad de la propiedad puede

18 SотO, Hernando de. The Mystery of Capital: Why Capitalism Triumphs in the West and Fails Everywhere Else. New York, 2000, p. 6. 
[...] proporcionar un indicio sobre la historia de los créditos del propietario, una dirección con la que se puede contar para el pago de deudas y la recaudación de impuestos, la base para la creación de utilidades públicas efectivas, y el cimiento para la creación de valores negociables (como los certificados de participación inmobiliarios), que pueden ser descontados y vendidos en mercados secundarios.

El resultado es que, incluso donde los países en desarrollo crean el marco legal para que los ciudadanos utilicen la propiedad para producir riqueza, la mayoría de los ciudadanos no pueden utilizar las leyes.

Esta línea de pensamiento muestra cuán remota resulta la teoría económica de la propiedad respecto de la realidad de todos los días. Asumiendo como natural la actual distribución de los recursos - pero trabajando, en verdad, dentro de las ideas auspiciadas por el FMI y el Banco Mundial sobre el rule of law, que rechaza la redistribución significativa- ${ }^{19}$ el movimiento para la «formalización» de los derechos de propiedad informal se topa con una ilusoria teoría para congelar y naturalizar aún más el statu quo. De Soto parece creer que es la teoría de la propiedad y no la pobreza, el analfabetismo, el hambre, la desesperación y la opresión consciente que ejercen los intereses de los poderosos lo que evita que los «sin tierra" recurran el derecho. Esta ideología económica, que resulta funcional para con los proyectos neoliberales, ni siquiera tiene en cuenta que, históricamente, los poderes coloniales han evitado, de manera sistemática, el desarrollo de mercados locales, porque el surgimiento de una clase media latinoamericana, precisamente, representa, hoy como ayer, el más peligroso enemigo del proyecto colonial. Cada vez que un gobierno latinoamericano ha pretendido defender la industria local a través de políticas proteccionistas mucho más claras que aquellas que se practican de manera rutinaria, incluso actualmente, en los países desarrollados, dicho gobierno se convierte en el objetivo de un ataque implacable, ideológico y físico, en aras de la libre competencia. Hacia el decenio 1830-1840, Juan Manuel de Rosas emprendió una política proteccionista en defensa de la naciente industria argentina, mediante la cual prohibió la importación de productos de hierro y de latón, así como de equipamiento para montar a caballo, ponchos, cinturones, productos agrícolas y otras mercaderías que se producían, tradicionalmente, en la zona central de Argentina, pero que se traían de Inglaterra, de fábricas más desarrolladas que tenían a su favor subsidios originados en el botín colonial, y que, por lo tanto, circulaban a precios muy bajos, con

19 He desarrollado una crítica de este "proyecto reaccionario» en MATTEI, U. "A Theory of Imperial Law. A Study on U.S. Hegemony and the Latin Resistance». Indiana Journal of Global Legal Studies, vol. 10, 2002. 
los cuales era imposible competir. Un bloqueo y, al final, una batalla acabaron con su gobierno en 1852. Su huella, como la de José Artigas, quien, treinta años antes, había osado poner en marcha una reforma agraria en lo que hoy es el territorio de Uruguay, ni siquiera se recuerda en nuestros días, porque la historia «oficial» la ha teñido de vileza. En el Perú, luego de la Independencia, no se dio ninguna iniciativa para proteger la próspera industria local de ponchos y tampoco se hizo ningún esfuerzo para implementar, realmente, las reformas agrarias impulsadas por Simón Bolívar en 1824, que buscaban acabar con el latifundio y proteger a los indígenas. En la producción colonial, los ponchos «nunca fueron tan perfectos como los tejidos originales que se elaboraban en tiempos de Pizarro, aunque la actividad económica, basada en la esclavitud de los indígenas, fue tremenda». ${ }^{20}$ Ello trajo como consecuencia que una industria naciente y significativa, establecida en zonas como Ayacucho y Tarma, desapareciera, simplemente, a manos de la competencia británica. Esta es la historia que el Banco Mundial nunca refiere cada vez que lamenta el subdesarrollo industrial latinoamericano.

Los especialistas han demostrado que las ideas de De Soto son técnicamente erróneas desde la perspectiva del derecho y que están basadas en una serie de mitos de tenor ideológico. ${ }^{21}$ Hendrix, por ejemplo, sostiene que los títulos, en efecto, no dan una prueba irrefutable de propiedad ni son garantía de protección frente a la inseguridad y el engaño:

En aquellas jurisdicciones donde existen registros públicos, como en la mayor parte de Estados Unidos, en Perú, en Bolivia, en Guatemala, en Venezuela y en otros países, el Gobierno no garantiza la propiedad de los predios, porque, simplemente, ya existe un documento registrado al respecto. Además, el derecho establece que si un documento se encuentra registrado, su inscripción hace público, para todos, el negocio de transferencia. Si el documento no está registrado, el negocio es eficaz únicamente entre las partes contratantes, aunque no medie inscripción. Pero contra un adquirente de buena fe, dicho negocio es inválido. El Gobierno tampoco garantiza, por otro lado, que el contenido de los documentos registrados sea confiable. En consecuencia, los sistemas registrales fracasan en lo que atañe al suministro de pruebas irrefutables de la propiedad, y brindan una menor protección contra la inseguridad y el engaño.

A pesar de la debilidad teórica y de las tendenciosas políticas que inspiran ideas como la ahora criticada y que presentan a la distribución imperialista de

20 Galeano, E. Op. cit., p. 176

21 HENDRIX, S. "The Myths of Property Rights». Arizona Journal of International and Comparative Law, vol. 12, 1995, p. 192. 
la riqueza, a lo sumo, como «uno de los problemas» y no como «el» problema que se debe enfrentar en la actualidad, el Instituto Libertad y Democracia, presidido por De Soto, ha conseguido plasmar sus propuestas de formalización en el decreto legislativo 803, del 22 marzo de 1996, con el cual se creó la Comisión de Formalización de la Propiedad Informal (COFOPRI), así como sus programas para la instalación y la estrategia que seguirá esta última organización. Sin embargo, el programa de «hipoteca popular», concebido por el Instituto de De Soto para permitir a los que contaban con títulos de propiedad hipotecar sus casas para obtener capital, solo consiguió que se constituyeran veinte hipotecas antes de ser cancelado. ${ }^{22}$

No es de sorprender que las ideas de De Soto fueran muy bien recibidas durante el mandato presidencial de Fujimori. El Gobierno peruano precedente gozó, desde luego, del aprecio de las instituciones financieras internacionales debido a sus políticas de libre comercio, favorecedoras del imperialismo internacional, así como por la violencia de la que hizo gala en el combate contra sus opositores sociales. Después de todo, la formalización de un titúlo de propiedad — tal cual lo señala el mismo De Soto - concede más poder de control y, por consiguiente, un sistema poderoso para aplacar la resistencia creada por la desesperación.

Mayor sorpresa causa constatar, como prueba evidente de la ambigüedad política de la retórica de los economistas, que algunas de las ideas de De Soto inspiran el paquete de reformas impulsadas por el presidente Lula, en Brasil.

Me ha sido imposible encontrar datos confiables y recientes sobre los índices de desigualdad en los niveles de riqueza y en la distribución de la propiedad en el Perú. Dichos índices ilustrarían el contexto social fundamental en el que todo derecho de propiedad, y, más en general, todo sistema de derecho privado, debe ser evaluado. En cambio, sí he conseguido procurarme interesante información sobre la población de poseedores precarios en Brasil, hacia los cuales apuntan también las propuestas de De Soto:

Como ocurre en muchos países desarrollados, existe una gran desigualdad en los niveles de riqueza y en la titularidad de propiedades entre los ciudadanos brasileños. El Departamento de Estado Norteamericano informa que son «enormes las disparidades aún existentes en la distribución del ingreso, pues la quinta parte más pobre de la población gana solamente el $2 \%$ del producto nacional, mientras que la décima parte más rica de la población percibe el 51\%» [cita de Gardiner] ${ }^{23}$ Esta

22 RosenberG, Tina. «So-So De Soto: A Peruvian Phony». The New Republic, 10 de julio de 1991, p. 21.

23 U.S. Department Of State. Brazil Human Rights Practices, 1995, Department of State Dispatch (marzo de 1996). 
desigualdad en los niveles de riqueza ha generado una escasez de vivienda que se ha estimado en 10 millones de unidades en 1992. En Brasil, el 46\% de los terrenos está en manos de ricos hacendados, que representan no más que el $1 \%$ de la población del país. Según el Instituto Brasileño de Geografía y Estadística, sólo el $3 \%$ de los terrenos es poseído por los pobres de las zonas rurales, que representan el $53 \%$ de la población del país. Muchos de los sin tierra están inconformes porque hay extensas porciones de tierra que se mantienen sin ser utilizadas en Brasil. No llama la atención que la desigualdad en la distribución de la propiedad de la tierra haya dado lugar a la ocupación precaria, y, como consecuencia, a violentas reacciones de los hacendados. ${ }^{24}$

Quinientos años de historia han demostrado que el derecho de propiedad de América Latina jamás ha sido capaz de resolver, por un período de tiempo que se pueda considerar significativo, ni la cuestión agraria ni los problemas de la industria. La razón de estos efectos puramente temporales, impropios para responder a las inherentes deficiencias locales, ha sido vista en la estructura internacional del capitalismo, interesado en mantener a América Latina como un espacio donde las actividades extractivas pueden desarrollarse a bajo costo. La entera estructura institucional de América Latina, y no solamente el derecho, está organizada en forma tal que facilita la división internacional de los papeles por desempeñar. Hoy en día, el derecho de propiedad intelectual reproduce esta estructura de dominación, incluso en un nivel más grande.

Los juristas tienen un importante papel y, por lo tanto, una importante responsabilidad en la reversión del estado de cosas que reina en el mundo de los negocios. No es por medio de reformas asistemáticas, ni de la formalización de títulos ni de una mayor importación de formas de pensamiento occidentales que los juristas pueden coadyuvar a la liberación de su país de la opresión extranjera y de la dependencia intelectual y material. No es prestando atención a programas que echan la culpa a las víctimas de las «carencias» a las que ellas se han visto forzadas a afrontar que los juristas pueden desempeñar un papel relevante en la era de globalización jurídica que estamos viviendo.

5. Con las posteriores operaciones de importación de normas de los países de Occidente, sea de la familia del civil law, sea de la familia del common law, se ha terminado generando en la mentalidad de los juristas la idea de que el derecho constituye un ejercicio técnico y neutral para la solución de

24 GaRdiner, Brian. "Squatters' Rights And Adverse Possession: A Search for Equitable Application of Property Laws». Indiana International \& Comparative Law Review, vol. 8, pp. 119, 149-50. 
problemas. Las particularidades y la historia locales son erradicadas y los profesionales del derecho formal son incapaces de marchar por un camino propio e independiente. La desmesura del Norte, de la mano con la resignación latinoamericana; el oportunismo y el divisionismo han conspirado para que un razonamiento jurídico crítico e independiente no pueda desarrollarse. Actitudes similares han impedido que se elaboren modelos de desarrollo independientes en otras áreas de la cultura y de la política, distintas del derecho. El resultado actual, que está ante nuestros ojos, es una clase de juristas cuyo papel sigue siendo marginal en la creacción de una sociedad mejor y más justa; lo que dicha clase hace es servir a objetivos contrarios, a los intereses de las potencias internacionales y a sus aliados que ejercen el poder local. En 1989, la caída del Muro de Berlín convenció al mundo de que solo existía un único camino posible para el desarrollo: el del capitalismo occidental, legitimado por la eficiencia económica y el individualismo implacable. Hoy, sin embargo, tenemos que admitir que el grado de injusticia que caracteriza este modelo de desarrollo, basado en una progresiva concentración de la propiedad en manos de una oligarquía y en una insostenible difusión de la pobreza, lo condena.

El mundo está en busca de nuevos modelos de desarrollo, de nuevas organizaciones sociales, de nuevas ideas jurídicas que tengan la posibilidad de oponerse a la noción de un derecho gobernado por intereses económicos, incapaz de administrar estos últimos. Pero ideas nuevas como estas solo pueden nacer en países que han vivido la opresión, que conocen los costos reales del capitalismo occidental, que comprenden que no existe futuro sin una distribución equitativa de los recursos, que no existe paz sin justicia. América Latina es, ni más ni menos, un entorno como el descrito. El tema de la distribución de la propiedad, de la igualdad social, de la insostenible naturaleza del orden mundial vigente está ante los ojos de los juristas, de los profesionales de la justicia y de las organizaciones sociales de América Latina en cada momento de su existencia. Frente a la actual división de la riqueza y a la actual distribución del poder, no existen sino dos actitudes: estar en contra o ser cómplice de ellas. En uno de mis trabajos he abogado por una Latin resistance, que sea capaz de conjurar el estado de cosas. Ahora lo hago por el nacimiento de una cultura jurídica latinoamericana cosmopolita y de resistencia, que sea crítica en sus percepciones y militante en sus objetivos y métodos; una cultura jurídica que sea capaz de abrir las puertas, de una vez por todas, a la comunicación y cooperación en el continente y cuyos actores puedan desempeñarse como líderes intelectuales para la resistencia en otros países explotados, que sufren, acaso, mucho más que ellos. El tema del derecho de propiedad y de la distribución de los recursos debe ser analizado con el esfuerzo de crear un contexto jurídico para una econo- 
mía independiente y libre, por vez primera, en más de quinientos años de historia, que se ponga al servicio de las multitudes locales y no de los monopolios internacionales y sus sucursales. Una estructura institucional adecuada permitiría que la economía dirija su mirada hacia el interior, y no hacia el exterior, y rompa el fenómeno de continuismo representado, sucesivamente, por la actividad extractiva de los conquistadores, la dominación de los capitalistas británicos y, ahora, por los planes de auste estructural auspiciados, con chantaje de por medio, por el FMI, al servicio de los intereses de Estados Unidos. La creación de esa nueva «constitución económica de la propiedad», basada en la solidaridad y en la redistribución y nacida en contextos tradicionalmente subordinados, sería, en realidad, como una nueva declaración de independencia, intelectual y económica, en un momento político excepcionalmente maduro para la unidad continental y para el pensamiento progresista. ${ }^{25}$

América Latina nació como un territorio único en los sueños y esperanzas de Simón Bolívar, José Artigas y José de San Martín. La misma idea alimentó, más tarde, los sueños de Ernesto Guevara de la Serna. La estructura de la fragmentación colonial, funcional para con los intereses de la dominación internacional, fue consolidada por las oligarquías que clamaban por la liberalización del comercio a través de los siglos XIX y XX. Ha sido una historia larga — que tal vez prosigue en nuestros días-, en la cual la comunicación con Europa resulta mucho más fácil que la comunicación interna. América Latina debe llegar a convertirse en un espacio jurídicamente, politicamente, económicamente y culturalmente unificado; debe desarrollar una cultura jurídica unificada, a lo mejor con un Código Civil unificado, y, ciertamente, con una constitución económica de solidaridad entre los oprimidos. Hay una necesidad crucial de rechazar la retórica imperialista de las "culpas» y de las "carencias», que son el arma ideológica del Banco Mundial y de sus burdos consejeros, y que es la única capaz de servir de base a sus absurdas recetas para el «desarrollo», basadas en la eficiencia. En un contexto donde existe un alto nivel de desempleo es absurdo proponer la importación de tecnología, la cual reduce la necesidad de mano de obra. En un contexto donde la industria local jamás se ha desarrollado, a causa de la injusta competencia internacional, es absurdo aceptar programas de libre comercio, como si no estuviera cabalmente demostrado, al cabo de cientos de años, que la inversión extranjera no devuelve nada de lo que toma a América Latina. Los juristas tienen la tarea de desarrollar nociones de justicia

25 Los gobiernos democráticamente elegidos, y de tendencia progresista, priman actualmente en América Latina en países como Brasil, Argentina, Venezuela, Perú y Uruguay. 
y de responsabilidad que permitan servir de base para que los gobiernos se liberen de las imposiciones de las instituciones financieras internacionales. Como sabe bien todo jurista que se respete, los deudores constituirán una fuerza poderosa si se unen y se apoyan en una teoría bien estructurada.

Los juristas deberían dotarse, a sí mismos, de una cultura cosmopolita que consiga romper las barreras del formalismo y purismo jurídicos, pero también las de los diálogos reservados para economistas. El modelo de educación jurídica de Pérez Perdomo, que presta atención a las relaciones entre derecho y sociedad, puede brindar un nuevo e importante ejemplo en esta línea de acción. Una vez que los juristas enriquezcan su cultura, más allá de letras muertas, de formalismos y discursos tecnocráticos, comprenderán cuánto de verdad encierra una frase del intelectual uruguayo Eduardo Galeano: «El desarrollo es un banquete al que pocos están invitados, y cuyos platos principales están reservados para los estómagos extranjeros».

Quizás algún día, cuando nazca este nuevo tipo de juristas, volveremos a reunirnos para celebrar el nacimiento de un Código panlatinoamericano, que sea eficaz, finalmente, en la búsqueda de la justicia social y capaz de brindar al mundo una contribución significativa para el rompimiento de las cadenas de la corporate domination. La capitalización de la energía de los deudores históricamente explotados, ubicada, finalmente, en el lugar que le corresponde, es la estrategia de liberación que someto a vuestra consideración esta noche. Para emprender esta tarea, de una magnitud nada común, resulta crucial entender que los intereses de los «entornos de recepción» del derecho no son los mismos que los intereses de los «entornos de producción", de modo que el derecho local y la ciencia jurídica deberían actuar en primera, y no en segunda, instancia. Las concepciones occidentales del derecho de propiedad, invariablemente egoístas, individualistas y reconocedoras de un precio para los instintos de acumulación sirven a los intereses de los entornos políticos en los que ellos son producidos, y deberían, por lo tanto, ser abandonadas y sustituidas por nuevas ideas, que sirvan a la gente de América Latina y no al enriquecimiento global. La importación de ideas y conceptos jurídicos obsoletos de Europa continental o Estados Unidos sirve a la cadena de dominación exactamente en la misma forma que lo hace la importación de tecnología obsoleta, que aplasta la innovación local y favorece la dependencia. Ha llegado el momento de explotar un nuevo y rico tesoro en América Latina: el tesoro de las culturas jurídicas alternativas. 